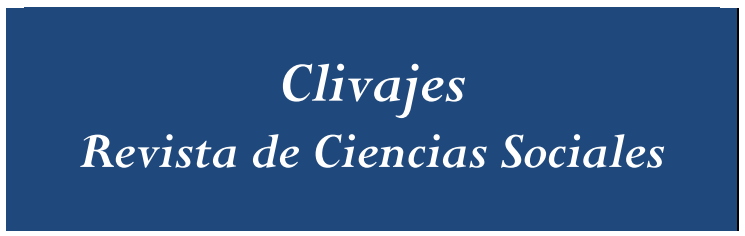

Clivajes. Revista de Ciencias Sociales ISSN: 2395-9495

https://goo.gl/HuwAmf IIH-S, UV, México

Rosa Nidia Buenfil Burgos

LÓGICAS DE INTELECCIÓN EN LA PRODUCCIÓN DE CONOCIMIENTOS: SU IMPORTANCIA EN LA INVESTIGACIÓN SOBRE MIGRANTES

Clivajes. Revista de Ciencias Sociales. Año V, número 9, enero-junio 2018, pp.27-49. Instituto de Investigaciones Histórico-Sociales Universidad Veracruzana. México

Recibido: 03-11-2017

Aceptado: 10-11-2017

Dictaminado: 05-12-2017

Publicado: 01-01-2018 


\title{
LÓGICAS DE INTELECCIÓN EN LA PRODUCCIÓN DE CONOCIMIENTOS: SU IMPORTANCIA EN LA INVESTIGACIÓN SOBRE MIGRANTES
}

\author{
Rosa Nidia Buenfil Burgos*
}

Resumen

Cuando se trata de procedimientos de investigación en ciencias sociales, es frecuente encontrar disquisiciones, prescripciones y, en el mejor de los casos, discusiones de teorías, metodologías, prescripciones técnicas, comparación de conceptos y nociones, incluso se llegan a discutir posicionamientos epistemológicos. En escasas ocasiones se discuten o al menos se tematizan los supuestos ontológicos, las estrategias de argumentación y mucho menos las lógicas que subyacen a la producción de conocimientos.

En este escrito, se problematizan lógicas de intelección tradicionalmente usadas para la descripción y explicación en ciencias sociales, tomando el caso de la migración, con base en un referente empírico que consta de información documental, observación y entrevistas a estudiantes, profesores y miembros de una comunidad rural. Se elaboran y ponen en juego otras lógicas y categorías, como la aporía y la indecidibilidad, con el fin de ubicar en qué medida arrojan luz o no, para caracterizar, comprender e interpretar las formas como estos entrevistados significan la migración.

Palabras clave: Migración, Aporía, Categorías y lógicas de intelección, Contextualidad

\section{INTRODUCCIÓN}

Pensar en las ciencias sociales exige reconocer las vicisitudes de un trayecto de conformación con marcas de muchas herencias, no necesariamente armónicas ni complementarias, que involucran tensiones e incompatibilidades concernientes a las posiciones ontológicas, epistemológicas, políticas, y éticas que en ellas participan. Se trata de una trayectoria histórica, de discontinuidades marcadas por acontecimientos que dislocan y son condición de posibilidad para la emergencia de nuevas articulaciones epistemológicas que guardarán registro de configuraciones previas. Las ciencias sociales pueden periodizar antecedentes y momentos fundacionales de esta trayectoria; no es éste el espacio para tan extensa empresa, ${ }^{1}$ pues lo que interesa señalar aquí es cómo ciertas lógicas han imperado en ese trayecto, marginando a otras, y cómo en otros momentos han sido excluidas de los cánones de la

* Ph.D. en Teoría Política por la Universidad de Essex, Inglaterra. Investigadora Titular, Nivel 3D, en el CINVESTAV-IPN. Miembro de la Academia Mexicana de las Ciencias y del Sistema Nacional de investigadores, Nivel III.

${ }^{1} \mathrm{Al}$ respecto puede consultarse L'Encyclopédie Dictionnaire raisonné des sciences, des arts et des métiers, de Denis Diderot, editada en Francia entre los años 1751 y 1772, y representativa de la Ilustración; también, Los cambios de paradigma en ciencia, de Kuhn (1971), y La historia social del conocimiento, de Peter Burke (2002). 
norma. Tomemos por ejemplo la certeza y la paradoja. En las elaboraciones de los griegos clásicos, fue en el debate entre socráticos y sofistas donde podía visibilizarse el uso intelectual de estos recursos. Más adelante, la balanza fue inclinándose a favor de la certeza, la apodicticidad, y la fuerza de intelección que reconocía el valor de la paradoja, la aporía y la contradicción fue perdiendo terreno.

La certeza podría venir de la divinidad y el misterio (teología medieval) o del pensamiento racional y científico (modernidad). El pensamiento de la duda tendría su solución teleológica en la forma, el concepto, la razón pura. La incertidumbre, la aporía y la paradoja se insinuarían como formas defectuosas del pensamiento $\mathrm{y}$, en el mejor de los casos, como punto de partida para el telos apodíctico, tan buscado tanto en las fenomenologías (Husserl, 1994 y Hegel, 1966) como en el positivismo filosófico y sociológico.

La intención de este artículo es visibilizar la productividad de estas fuerzas y recursos de intelección, que denomino "lógicas" (la paradoja, la aporía y la idecidibilidad), para desedimentar su asociación con el razonamiento defectuoso y estéril, y reactivar sus sentidos tanto de la razón práctica y el pensamiento contextualizado, como de la productividad propia del pensar en la tensión.

Por ello, en la primera sección del texto, despliego el contexto epistemológico de mis consideraciones; en la segunda, expongo un ejemplo concreto de investigación para desmenuzar implicaciones epistemológicas y políticas del uso de una u otra lógica; y, en la tercera sección, anudo planteamientos y posicionamientos sobre recurrir a una u otra lógica en la investigación.

\section{CONTEXTO EPISTEMOlÓgiCO DE LA IMPORTANCIA DE LAS LÓGICAS DE INTELECCiÓN: LA INVESTIGACIÓN DESDE EL ANÁLISIS POLÍTICO DE DISCURSO (APD)}

Un punto de partida es el reconocimiento de que la investigación es producción de conocimientos dentro de ciertos cánones de validez consensuados por una comunidad científica. Si bien estos cánones cambian con el tiempo, y difícilmente gozan de un consenso total, no pueden ser ignorados, ya que son parte de las reglas del juego (de la gramática, diría Wittgenstein, 1953). Uno de estos cánones alude al mayor o menor grado de consistencia conceptual, metodológica y analítica que debe caracterizar al conocimiento "científico" (a diferencia del conocimiento místico, mágico, religioso, metafísico, e incluso de la opinión pública y el sentido común). La dimensión teórica, desde la perspectiva aquí asumida, involucra posicionamientos ontológicos y epistemológicos; lógicas de intelección y trama conceptual); es constitutiva de la producción de conocimientos, porque permite al 
investigador tener un referente distinto a la inmediatez y el sentido común para contrastar sus percepciones y registros de los procesos que examina. Aún más, si el conocimiento que se produce sobre lo social tiene como parte de su referente empírico a este sentido común, saber público, opinión admitida, creencias, y demás, requiere, de manera ineludible, de un cuerpo conceptual que le permita una distancia mínima de su referente empírico para poder analizarlo e interpretarlo.

Una vez ubicado el lugar de las lógicas en el registro teórico de la investigación, es importante examinar del uso de las teorías: cómo se incorporan y qué efectos genera lo anterior en el conocimiento producido. Existen usos estériles de la teoría, bastante generalizados: ${ }^{2}$ usos ingenuos, rituales o normativos, teoricistas, fatuos u ostentosos, defensivos, y otros que además obturan la relación con la dimensión situada del problema; también hay usos descalificadores: el práctico, el metodológico y el político, y seguramente otros más. Para comprender la importancia de lo teórico y a la vez evitar los excesos en el uso de las teorías en la investigación, conviene identificar y poner en tela de juicio estos usos, y otros cuyos efectos sean similares.

Hay también diversas formas de introducir productivamente lo teórico en la investigación, que conllevan lógicas generalmente desdeñadas: usos para problematizar lo que aparece como inmediato, normal o natural; usos de las teorías que exigen un vínculo estrecho con las particularidades del tema estudiado; usos para contrastar distintas aproximaciones a un mismo tema, brindando así una apoyatura que, junto con el recuento de las características del proceso investigado, posibilitan interpretaciones plausibles; usos en los que se pone a prueba la capacidad heurística, analítica, interpretativa o explicativa de las teorías mismas, frente a las exigencias de las preguntas de investigación y por las características particulares del referente empírico; usos en los que lo conceptual no se repite o "aplica", sino se recrea en cada investigación particular (Saur, 2008a); usos en los que incluso se complementa las teorías mediante la formulación de categorías intermedias. $^{3}$

En este plano, nociones, lógicas y posicionamientos onto-epistemológicos operan en forma parcial o radicalmente distinta a como intervienen en los usos estériles antes comentados. La teoría solamente se opone a la práctica, cuando investigadores y usuarios de las teorías tienen una concepción ilustrada o hacen un mal uso de ellas y las toman como elementos inconexos, o cuando se quiere forzar la práctica para responder a una

\footnotetext{
${ }^{2}$ Ver desarrollo en Buenfil (2006), desde el emplazamiento del Análisis político de discurso (APD, en adelante) en Jiménez, M.A. (Coord.) (2006).

${ }^{3}$ Para la discusión de la categoría intermedia como herramienta metodológica, ver Saur (2008b) y Buenfil (2008); para la producción y uso de categorías intermedias, ver, p. ej., Ruiz (2005), Echavarría (2007), Navarrete (2008) y Padierna (2009).
} 
teoría. Las teorías sirven o no sirven según la forma como las pongamos en acción; en otras palabras, somos los investigadores los que las usamos de manera más o menos rigurosa, más o menos imprecisa; más o menos mecánica, más o menos creativa, más o menos rígida, más o menos flexible. Dicho de otro modo, la responsabilidad epistémica, política y ética de los usos de la teoría recae en los investigadores y no en las teorías mismas.

Por fortuna, como se mencionó líneas arriba, existen múltiples formas de entender qué es la teoría y cómo opera en cada caso de producción de conocimiento. Lo que sostengo es que si la teoría se ubica como un elemento del proceso tríadico en cuya interconexión y ajuste se produce el objeto de estudio, otros usos más productivos de dicha teoría pueden ensayarse. Este proceso triádico abarca diversos procedimientos metodológicos en la investigación. Por metodología no entiendo exclusivamente las diversas estrategias de recolección de la información en un estudio, e incluso su tratamiento analítico, sino todo un proceso de articulación y ajuste permanente de tres esferas:

1) la dimensión teórica, que involucra la búsqueda de consistencia entre al menos tres ámbitos: a) el de los principios ontológicos y epistemológicos, b) el concerniente al armado de un cuerpo conceptual de apoyo y c) el que alude a una apoyatura en lógicas de intelección;

2) el referente empírico documentado, que puede estar compuesto de diversos soportes materiales (impresos, pictóricos, videograbaciones, etc.) y códigos variados (lingüísticos, icónicos, etc.), e involucra tanto el proceso que se analizará, como las condiciones en que se produjo;

3) las preguntas del investigador, que además involucran un mínimo conocimiento del campo problemático y lo que se ha investigado al respecto (Figura 1).

Lo que intento enfatizar es que el referente empírico participa, junto con el referente teórico y las preguntas del investigador, en la construcción del objeto de estudio, por lo cual este último es ya un híbrido que involucra huellas de la subjetividad del investigador, huellas de la particularidad histórica (i.e., contextuada o situada) del referente empírico, y marcas del aparato crítico con cuyos lentes se enfocan ciertas áreas y se difuminan otras. Dicho de otra manera, el objeto de estudio involucra una construcción y un ajuste constante entre los tres ámbitos mencionados. Así, en el referente empírico, la teoría y las preguntas están siempre presentes en la elección de formas y estrategias de recuperación de la información, y su análisis se ve afectado por el acceso a las narrativas disponibles. 
Ambos aspectos se deben ajustar según la ubicación de los actores y momentos clave relacionados con el objeto de interés, que jugará un papel importante en la exploración de técnicas de análisis disponibles y la construcción de categorías intermedias (ex profeso de cada investigación), que son punto de intersección entre el cuerpo conceptual que informa la investigación, las técnicas de análisis disponibles y lo que el referente documentado les demanda.

De manera equivalente, en el referente teórico intervienen permanentemente las preguntas de investigación y el referente empírico, tanto en la articulación disciplinaria, lógica y conceptual, como en la trama onto-epistemológica en la cual se sostiene y compatibiliza la anterior. Esto podría esquematizarse de la siguiente manera:

Figura 1. Papel de la teoría en la investigación

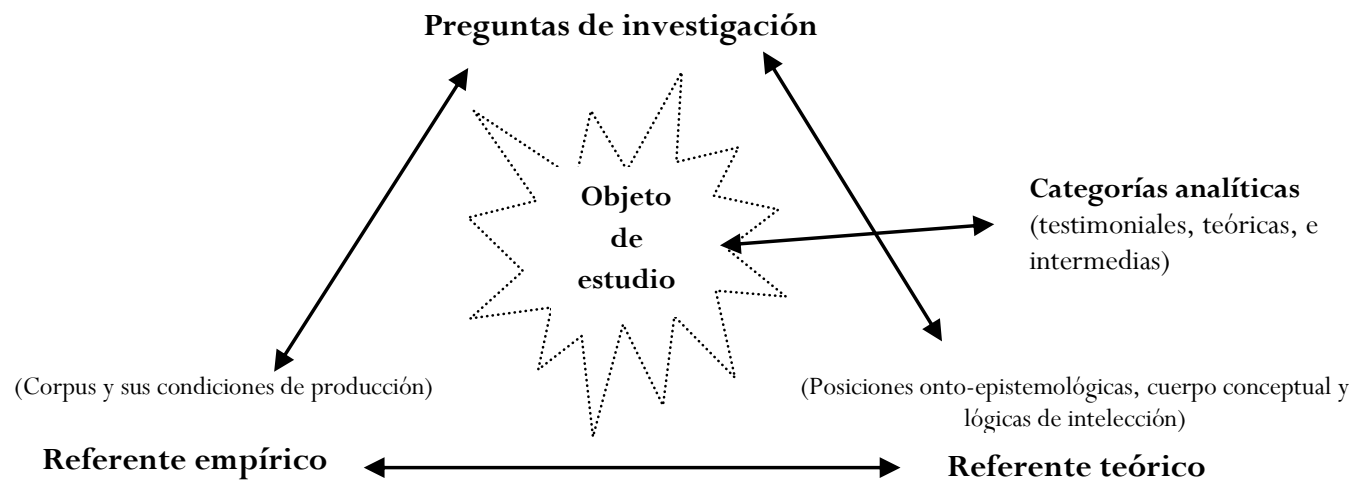

(Tensión irresoluble y ajuste permanente)

Fuente: Buenfil, R. N. y Navarrete, Z. (2008: 14).

Desde el punto de vista de la articulación de posicionamientos onto-epistémicos, de un cuerpo conceptual y de lógicas de intelección, en el estudio de las ciencias sociales destacan por ejemplo:

- el entretejimiento de miradas disciplinarias (sociológica, pedagógica, antropológica, histórica, filosófica, sociológica, psicoanalítica, etcétera);

- la articulación de nociones y lógicas de intelección, procedentes de paradigmas no sólo ajenos, sino a veces antagónicos, como los representados por el pragmatismo filosófico, el historicismo marxista, el estructuralismo, la crítica a la metafísica de la presencia y de los orígenes; el rechazo a una noción de identidad social fija y suturada; la objeción a una lógica causal dura y su reemplazo por la 
sobredeterminación; la tensión irresoluble o la indecidibilidad, por mencionar algunas. ${ }^{4}$ Se abundará en esto más adelante.

En cuanto a las articulaciones teóricas que abrevan de posiciones distintas, es pertinente precisar que, en búsqueda de la mayor consistencia posible, desplegamos estrategias de vigilancia epistemológica en nuestras propias investigaciones, observando los supuestos que subyacen a los insumos disciplinarios y teóricos que combinamos y cuidando que no sean incompatibles (en cuyo caso desmontamos la herramienta específica que intentamos recuperar de su contexto de procedencia, mostramos las incompatibilidades y argumentamos la forma en que su uso en un contexto epistémico diferente resignifica el recurso mencionado. 5 Esto permite la exploración de otras formas de significar los conceptos, articulándolos a principios distintos a los que inicialmente los ordenaban. Ello es una condición para establecer equivalencias entre lógicas de construcción del conocimiento y para compatibilizar categorías y conceptos procedentes de paradigmas distintos. En esta posibilidad se sostiene el entramado de lógicas y conceptos de procedencia teórica diversa.

Además de argumentos onto-epistemológicos y conceptuales procedentes de diversos campos, es conveniente caracterizar algunas lógicas que nos permiten otras figuras de intelección, otras formas de disquisición, por mucho tiempo abandonadas y hasta descalificadas por el pensamiento racionalista; por ejemplo, la lógica aporética, la paradoja, entre otras.

Con la expresión "lógicas de intelección" me refiero a estrategias que nos permiten imaginar relaciones entre las nociones con las que entendemos los componentes de nuestro objeto, para estar en posibilidad de comprenderlo, interpretarlo, dar cuenta de él. Éstas aluden a orientaciones epistémicas y fuerzas intelectuales en uso y enmarcadas también en las grandes tradiciones de pensamiento y sus batallas. Me refiero a las fuerzas del intelecto que estuvieron al servicio de las intuiciones, percepciones e ideas claras y distintas (Descartes,

\footnotetext{
${ }^{4}$ Para abundar en la elaboración de estas lógicas, ver, p. ej., Buenfil y Navarrete (2008).

${ }^{5}$ Por ejemplo, en el campo del análisis de discurso, tenemos conocimiento, desde Ferdinand de Saussure, del carácter relacional, diferencial del signo, además de todo el despliegue crítico del estructuralismo lingüístico que condujo al surgimiento del posestructuralismo, en especial Derrida (1987). De suyo, esta tradición es ajena a la de la Filosofía del Lenguaje. Con Wittgenstein, encontramos argumentos para sostener la relación constitutiva entre el uso y la significación en los juegos de lenguaje, normados convencionalmente (incorporando además los desarrollos de la pragmática anglosajona, en especial de Rorty, 1991), en la problematización del carácter discursivo del conocimiento y el carácter predicativo de toda proposición de verdad. Entre estas dos tradiciones es posible construir equivalencias en cuanto al carácter relacional y contextual de la significación (desde luego, sin olvidar las diferencias sustantivas entre ambas. Staten, 1985, ha mostrado la productividad de combinar la propuesta de Wittgenstein con el ejercicio deconstructivo derrideano -i.e. reactivar las categorías, trabajar con los conceptos sacudiendo sedimentos y buscando la contingencia de las articulaciones que los fijaron en un significado y los amarraron a un paradigma), a partir de una serie de presupuestos ontológicos, epistemológicos y teóricos que comparten ambas propuestas.
} 
1647), a la certeza y la apodicticidad (Husserl, 1994 o 1997): la causalidad necesaria y suficiente (de tipo múltiple o monádico), ${ }^{6}$ la determinación, la teleología, entre las más sobresalientes. En el APD, sin excluir el valor heurístico que eventualmente pueden tener lógicas atesoradas por el pensamiento ilustrado, se reactivan otras fuerzas de intelección que fueron relegadas de y eventualmente desprestigiadas por los cánones del pensamiento legítimo y la cientificidad. Me detendré solamente en algunos casos de lógicas que me interesa reactivar.

1. La tensión irresoluble pone en juego el conflicto y sus resultantes, como posibilidad instituyente; a diferencia de la figura del justo medio aristotélico (que resuelve y erradica la tensión, o la de la síntesis dialéctica en la que una lógica fundante y autodesplegable absorbe, explica el movimiento y resuelve la antítesis). Para ilustrar la lógica de la tensión nos referimos, por ejemplo, al vínculo entre necesidad y contingencia, en la cual la antítesis nunca se resuelve.

2. La paradoja se sustenta en significaciones y valores naturalizados, aparentemente incontrovertibles, y los pone a prueba al llevarlos a conclusiones, social o lógicamente, inaceptables o contradictorias; de esta manera, contribuye al despliegue del pensamiento. Tal forma de indagación puede rastrearse desde los griegos, especialmente los sofistas (siglo IV a.C.), y posteriormente, con atención específica de Pascal (1623) y Kierkegaard (1813), hasta los escritos sobre lógica de Bertrand Russell (1872-1970).

3. La aporía hace visible el carácter insoluble de un problema y, al hacerlo, saca provecho, pues despliega numerosas posibles alternativas; opera como una forma particular de problematización que, en vez de imponer un subterfugio insostenible, acepta la complejidad y la posibilidad de lo irresoluble. Me refiero, por ejemplo, a cuando algo es a la vez necesario e imposible. ${ }^{7}$ Regresaré a esta lógica en el siguiente apartado.

4. La sobredeterminación ${ }^{8}$ es incompatible con toda idea de "determinación en última instancia" (Laclau y Mouffe, 1987) de causalidad dura y fija, y, en cambio, opera como una especie de “casualidad” móvil e impura, abierta a la interpretación

${ }^{6}$ En las ciencias médicas y demográficas, causa suficiente: si el factor (causa) está presente, el efecto (enfermedad) siempre ocurre; causa necesaria: si el factor (causa) está ausente, el efecto no puede ocurrir.

${ }^{7}$ Inicialmente, la aporía socrática se ejemplificaba al asociar la virtud y el conocimiento, llegando a la conclusión de que nadie hace daño sabiéndolo, o nadie sabe lo que quiere decir cuando usa un término, a menos que pueda proporcionar una definición explícita de él.

8 "Sobredeterminació" es un concepto que Althusser recupera del psicoanálisis e incorpora por primera vez en el marxismo, precisamente para problematizar la idea de contradicción en Marx (Althusser, 1969); y Laclau y Mouffe (1987) lo radicalizan, enfatizando el carácter simbólico de toda relación social y la disposición relacional e impura de toda identidad. 
infinita. Esto implica los siguientes rasgos: por una parte, al tiempo que captura parcialmente trazos de la génesis de un proceso, reconoce que éstos proceden de otros ámbitos distintos al del proceso en cuestión, que opera un desplazamiento o reenvío simbólico, por lo cual siempre estamos ante la presencia de unas identidades en otras (son entonces identidades "contaminadas" irremediablemente); por otra parte, al tiempo que busca las fuerzas que irrumpen (Foucault 1979) en el proceso de gestación de un régimen, una ley, un sistema de significación, reconoce que en su emergencia, más que buscar una esencia, nos enfrenta al encadenamiento ineludible de contingencias (fusión de elementos en unidad de ruptura).

5. La indecidibilidad (Derrida, 1987), como estrategia de inteligibilidad, nos ofrece una alternativa a la lógica de disyunción o dilema heredada (e.g. blanco o negro, interno o externo, caja de Pandora o panacea); comparte la lógica de la tensión constitutiva y nos permite jugar con una figura de conjunción aporética: una lógica que no se concibe como un dualismo de dos entidades positivas que se oponen (por ejemplo, cuerpo y alma), ni tampoco se refiere al "justo medio" aristotélico (que resuelve la oposición en un punto medio), sino que permite mirar lo ambivalente, lo que es interno y a la vez externo. Nos referimos, por ejemplo, a cómo decidir si una puerta está dentro o fuera: es aquello que separa adentro y a la vez une afuera. Plantas medicinales, como la digitalina, que son remedio en una dosis y a la vez veneno en otra. A esto regresaré en el ejemplo de la sección siguiente.

Lejos de pretender una nueva normativa teórica, lo que se ha intentado hasta ahora es precisamente sacudir algunos sedimentos que, aunque ya erosionados en varios ángulos, persisten en las culturas institucionales de la investigación social. Se ha procurado criticar herencias que reducen las posibilidades analíticas e interpretativas de la teoría, que empobrecen su productividad y la rigidizan formalmente, deteriorando su sentido y potencial.

Si no esencializamos las teorías, como en su versión ilustrada, podemos cuestionar profundamente las pretensiones fundacionales de algunas de ellas, sin que eso excluya la posibilidad de otras con pretensiones distintas (no trascendentales a priori, sin estatutos epistemológicos pretendidamente superiores, sin reclamos de objetividad neutral, que asuman su carácter situado, contextual y contestable) ni que podamos continuar el debate en la guerra de interpretaciones de Nietzsche, e inventar, como el ironista de Rorty (1991), nuevos lenguajes para construir una mejor realidad. 


\section{EJEMPLO SOBRE LAS LÓGICAS EN LA INVESTIGACIÓN EN CIENCIAS SOCIALES}

Con la finalidad de visibilizar cómo operan las lógicas en la investigación, tomaré un caso sobre la migración y expondré a qué interpretaciones se llega siguiendo una lógica canónica y a cuáles siguiendo una lógica aporética.

El tema de la migración se trata, con frecuencia, en un marco de denuncia de fenómenos opresivos y necesidades estructurales, derivadas del subdesarrollo y el empobrecimiento (McDowel, 1996) y de la globalización, ${ }^{9}$ ya se trate de migraciones forzadas por motivos políticos, o por motivos laborales, culturales, etc. (Bar-Din, 2008; Davis, 1993; Valenzuela, 1999). Si bien comparto la importancia de visibilizar la dimensión opresiva de las migraciones forzadas, es también valioso evidenciar la dimensión educativa, productiva y de empoderamiento que tiene lugar, simultáneamente, en este tránsito poblacional. En las siguientes líneas, examinaré cómo juegan las categorías y lógicas de intelección en la interpretación de un referente empírico concreto, mostrando lo que ofrecen unas y otras. ${ }^{10}$

La migración de jóvenes del Valle del Mezquital, Hidalgo, tiene una historia y un contexto que no desarrollaré aquí, pero que marcan significativamente las formas como los jóvenes conciben su proceso. Gómez Gallegos (2012) señala que los primeros antecedentes de migración hñähñú a Estados Unidos datan de los años treinta; sin embargo, el despoblamiento del Valle del Mezquital empezó a ser más visible a finales de los años ochenta. La mayor proporción de hogares con miembros migrantes se ubica en la mitad de los años noventa ${ }^{11}$ y la circulación de población joven también se dirige hacia las zonas urbanas del país. Se ha incrementado el número de jóvenes que manifiestan explícitamente su rechazo a la idea de ir a Estados Unidos y buscan alternativas a la migración; muchos de ellos están en la búsqueda de opciones para ingresar a la educación superior.

${ }^{9}$ Es crucial historizar las migraciones desde Asia al continente americano, para entender que éstas no son producidas por la globalización del sistema capitalista en su fase neoliberal. En los comienzos mismos de la historia del mundo occidental, los relatos imbricados del judaísmo y la cristiandad, los éxodos pre-capitalistas por motivos y conflictos religiosos y étnicos, muestran que las migraciones no se iniciaron en el siglo XX. Sin duda, las migraciones con sus rasgos específicos, en localidades contiguas, intensificadas por la interconexión e interdependencia de sistemas financieros a una escala global, han exacerbado tal movilización (lo cual suele sintetizarse en la expresión globalización del neo-liberalismo, expresión simplificadora que, en mi opinión, tendría que examinarse con más precisión).

${ }^{10}$ He recurrido a testimonios de estudiantes, profesores y miembros de una comunidad rural en el Estado de Hidalgo, tomando en préstamo información contenida y procesada en la investigación de Ángeles Gómez Gallegos (2012).

${ }^{11}$ El $24.7 \%$ del grupo de entre 15 y 19 años edad y el $22.4 \%$ de entre 20 y 24 años migraron en la segunda mitad de los noventa (Quezada, 2008); casi la mitad son jóvenes de entre 15 y 24 años de edad (Gómez Gallegos, 2012: 61). 
El horizonte de estos jóvenes está marcado por la migración y oscila entre el trabajo en Estados Unidos, un lugar distinto a su lugar de residencia, o el ingreso a las universidades accesibles. Si ingresan a una, de todas formas migran para vivir en lugares cercanos a ella. El presente y el futuro de quienes no emigran también son bastante inciertos. Los jóvenes que no se mantienen con la idea de profesionalizarse y quienes no son admitidos en ninguna institución trabajan en sus comunidades, pero muchas veces se trasladan hacia donde hay empleos, aunque sea temporales (el campo, comercio o la construcción primordialmente). Por otra parte, la idea de moverse de su lugar de residencia está claramente presente en su horizonte de futuro y es casi tan natural como formar su propia familia. Ante la pregunta de dónde les gustaría vivir, 62 de los 90 encuestados responde que fuera de su comunidad y 26 que en su comunidad; 2 responden que en la playa (Gómez Gallegos, 2012: 22).

Para los jóvenes del Valle del Mezquital, las desigualdades no sólo están marcadas por su origen étnico y rural, sino además por lo que hacen durante su vida productiva, por sus intentos de superar un limitado nivel de vida en sus comunidades y llevarlo al de desarrollo, y también por el nivel de éxito derivado de estos intentos (éxito entendido como mejoras laborales, profesionales, de consumo y servicios, en su calidad de vida, etc.). La migración está en el repertorio de vías para lograr tales mejoras y a veces es entendida como un éxito en sí misma.

Siguiendo la descripción de Gómez Gallegos (2012: 48), es posible observar diversas transformaciones culturales, como parte de los efectos de la migración en estas comunidades; veamos sólo tres ejemplos: lo que toca a la situación cotidiana y composición de la familia, lo concerniente a vestimenta, y lo relativo a la propia arquitectura local.

En las familias del lugar es común la ausencia de algún integrante, debido a este fenómeno, por lo que la composición familiar suele modificarse: madres e hijos jóvenes y/o niños, a veces abuelas, hijas y nietos. En ocasiones hay varias hermanas, con sus hijos, viviendo con la madre. También hay hogares de abuela y nietos, en casos en que madre y padre han emigrado, o madres solteras emigran para ser el sostén del hogar. Regularmente migran el jefe de familia o los hijos mayores, quienes constituyen el principal sostén de la casa, pero no en el único. Muchas veces, las familias que permanecen en la comunidad han emprendido también alguna actividad económica para apoyar las remesas enviadas desde Estados Unidos, ya sea instalando un negocio en la casa familiar o en la ciudad de Ixmiquilpan, o bien labrando algún terreno familiar (Gómez, 2012: 48).

La vestimenta tradicional de adultos y niños, de hombres y mujeres, va siendo también alterada poco a poco: las jóvenes que estudian o trabajan sustituyen las faldas largas, las blusas típicas de manta blanca y los rebozos, por ropa de mezclilla, playeras de algodón o 
telas sintéticas, generalmente cómoda (o "de moda"), y zapatos-tenis, con mucho mayor frecuencia que huaraches, zapatos cerrados o sandalias.

De acuerdo con la misma fuente, la arquitectura del Valle del Mezquital muestra una adaptación de elementos propios en coexistencia con elementos de la cultura estadounidense, que ha fluido durante varios años en estas comunidades de elevado índice migratorio. En las casas de reciente construcción, se percibe la influencia de la arquitectura angloamericana, que contrasta con las casas tradicionales de la comunidad. Las casas recientes con techos de dos aguas, algunas con chimenea, cuartos de servicio, de herramientas y de lavado de ropa; los jardines al frente y la cochera a un costado, no se asemejan a los de clase media de nuestro país; es un estilo traído de Estados Unidos.

Sin embargo, la modificación en el diseño de las viviendas no sólo es promovida por la migración de retorno, también por la definitiva. Los migrantes que permanecen más tiempo fuera de sus comunidades, o que ya no regresan, han construido casas que permanecen deshabitadas durante varios años. En casas terminadas y pintadas con tonalidades fuertes, se agregan acabados con materiales y estilos locales; por ejemplo, los acabados de loseta porcelanizada, azulejo y tirol planchado en muros. Las fachadas tienen el aplanado tradicional mexicano, con cemento, y las ventanas de herrería negra o aluminio. Esta combinación da como resultado un estilo arquitectónico anglo-mestizo que, en un medio semidesértico, semeja una geografía superpuesta. Las casas con esta arquitectura son significadas como muestra de ascenso social y forma de mantener contacto con las comunidades de origen (Gómez Gallegos, 2012: 48-53).

Otras transformaciones culturales son visibles en el uso de mini-pantallas y monitores de televisión en el transporte público de pasajeros, en el uso de teléfonos celulares, en el establecimiento de locales con servicio de Internet -aun en comunidades alejadas de los centros de los municipios-, en el entretenimiento de los niños con juegos en las computadoras, en el uso cada vez más cotidiano de las motocicletas y el consumo de comida chatarra, etc.

La influencia de los migrantes ha sido definitiva en la vida de las comunidades. Las expectativas de los niños han cambiado a partir de ésta. El director de la primaria local comenta que algunos niños ya no hablan de lo que quieren ser cuando sean grandes, sino que hablan de migrar (Gómez Gallegos, 2012: 53). Una de las razones de la migración es el ascenso social, marcado por la adquisición o mejora visible de un bien inmueble; esto es parte de lo que implica una reorganización espacial. La reorganización del espacio comunitario sigue siendo un referente del individuo, porque el lugar de origen es un marcador identitario. 
La migración implica ausencia física de las personas en las comunidades y, paradójicamente, vuelven a estar presentes cuando la gente recibe las remesas; las evoca en sus conversaciones o cuando se refieren a las viviendas en construcción. De acuerdo con una habitante del lugar, el cambio de residencia de las familias es común, ya que, si bien hay casas de ladrillo, muchas de ellas no son habitadas por sus dueños, quienes viven en Ixmiquilpan, en otras ciudades o en Estados Unidos.

En cuanto a la migración interna, quizá sus efectos en la vida comunitaria sean menos visibles. Ya sea por razones laborales o por motivos de oportunidad escolar, en las comunidades del Valle del Mezquital, se observa también una importante corriente migratoria. Los jóvenes emigran como algo ya incorporado a su horizonte de futuro y muestran una disposición naturalizada para esta movilidad, si las opciones laborales los distancian de sus lugares de origen y, en menor medida, aunque también como algo ya muy interiorizado, para mejores oportunidades en su profesionalización. La información oficial de la Universidad Tecnológica de Hidalgo muestra que la movilidad laboral es alta; por ejemplo, el 59\% de los egresados de la generación III-08 que trabajan, lo hace en la zona de influencia de la universidad, y el 41\% lo hace en otro Estado. El 56\% de los egresados de la generación III-07 que trabajan, lo hace en la zona de influencia institucional, y el 44\% en otro Estado (Gómez Gallegos, 2012: 66).

Concluyo esta sección descriptiva aludiendo al horizonte imaginario de futuro, frecuente entre los jóvenes de la zona mencionada, aprovechando una entrevista incluida en la multimencionada investigación.

1. ¿Qué vas a hacer cuando termines tu carrera?

Primero que nada, quiero encontrar un trabajo que realmente me convenza, no quedarme en lo que es el Estado de México en Jilotepec, me gustaría irme a San Luis Potosí, a Querétaro o a Monterrey, buscar mejores oportunidades para laborar.

2. ¿Por qué esas ciudades?

Porque son las mejores ciudades que tienen más desarrollo.

3. ¿Te ves trabajando en una empresa grande, mediana o en un negocio propio?

Me gustaría tener un negocio propio, pero también me gustaría estar trabajando en una empresa grande.

4. ¿Negocio de qué te gustaría tener?

Como una cadena de tiendas, algo que sea amplio para hacer lo que yo quiero. 
5. ¿Consideras que tienes alguna dificultad para adaptarte, tú saldrías de tu comunidad para ir a vivir a otro lado?

De hecho, ya he salido de mi comunidad para vivir en otro lado.

6. ¿Cuánto tiempo saliste?

Estuve un año en Villa del Carbón y otro en Tejupilco, y realmente sí es difícil estar en Tejupilco, aguantar la primera quincena.

7. ¿Por qué?

Uno por las condiciones climáticas y otro porque (...) donde estuve laborando, era una comunidad rural, no hay ni caminos, había que caminar mucho, las casas son de adobe, de teja, por todos lados se mete el agua, hay alacranes, hay muchos peligros y pues me adapté

8. ¿Tus hermanos han salido a otros lugares a vivir?

No, todos viven en Jilotepec, [sic] uno de mis hermanos está trabajando en México.

9. ¿Tiene varios años allá o recientemente se fue?

Tiene varios años allá.

10. ¿Y cómo lo ves recientemente, ha cambiado?

Sí, en su forma de pensar de vestir, sí ha cambiado mucho.

11. ¿Y eso cómo lo ves?

Pues parece ser un cambio para mejorar, para vivir mejor, para superarse.

(Gómez, Gallegos, 2012: 215)

En los dos segmentos semánticos de esta entrevista (horizonte de futuro - preguntas 1 a 4- y migración - pregunta 5 en adelante) puede observarse que la idea de migrar está incorporada al horizonte de la vida por venir, naturalizada; que dicha idea es motivada en forma diversa, y aunque temporalmente pueda representarse como algo difícil, quienes piensan migrar o emigran se adaptan y significan los cambios como vía para mejorar.

La descripción anterior me permite exponer algunas consideraciones metodológicas. Aunque algunos investigadores sostienen que "los datos hablan por sí mismos", argumentaré que los investigadores hablamos por ellos y decimos cosas en las que hay inscripciones que van mucho más allá de lo que los datos "dicen". Precisamente por ese plus que quien investiga imprime en los datos, es crucial saber algo de lo que está en juego en tal inscripción. En primer lugar, están las implicaciones subjetivas propias de la persona que se 
interesa cognoscitivamente por el asunto: su historia, sus preferencias teóricas y temáticas, sus conocimientos previos de la cuestión, y así sucesivamente; en segundo lugar, están los recursos de comprensión que tiene a la mano: conceptos, lógicas de intelección, posicionamientos epistemológicos y ontológicos, políticos y éticos. La mutua contaminación de estos dos planos es lo que se inscribe en la elección y registro de la información empírica y en la construcción del dato, su análisis y su interpretación. En este segundo aspecto, el de los conceptos y lógicas, me detendré para desplegar algunas de sus implicaciones.

Cuando uno observa fenómenos como la migración recién presentada, no es suficiente interpretar con los recursos tradicionales, pues no alcanzan para comprender (más que en forma binaria y maniquea) los matices, inconsistencias, ${ }^{12}$ y paradojas de las vivencias narradas por los informantes. Entender sus decisiones sobre "irse o quedarse", en términos de pérdida o ganancia, de desarraigo o arraigo; en suma, la lógica binaria: bueno o malo, dominación neoliberal o emancipación, lógicas predominantes en importantes investigaciones sobre la migración, ${ }^{13}$ resulta claramente insuficiente en términos de conocimiento y nos encamina más hacia el juicio sobre lo acontecido que a la profundidad y precisión sobre el fenómeno (lo que ocurre y cómo lo significa y lo narra el protagonista).

Sin menospreciar el valor analítico de las lógicas predominantes en el pensamiento ilustrado, que por siglos han orientado la producción científica y filosófica, me interesa reactivar otras fuerzas de intelección relegadas, desprestigiadas y eventualmente excluidas de los cánones del pensamiento legítimo y la cientificidad. Ahora me detendré en la paradoja, la aporía y la indecidibilidad.

Como señalé en la sección previa, La paradoja pone a prueba significaciones y valores naturalizados, aparentemente incontrovertibles, al llevarlos a conclusiones inaceptables o contradictorias, contribuyendo así al desarrollo del pensamiento (desde los griegos, pasando por Pascal y Kierkegaard, hasta los escritos sobre Lógica de Bertrand Russell). ${ }^{14}$

${ }^{12}$ Como ante la pregunta sobre si han salido en su familia, el informante señala que "no, todos viven en Jilotepec”, y luego, sin mayor transición, sostiene que uno de sus hermanos está en México (líneas 25 y 26 de la transcripción).

13 (1) Within a frame of accusations of oppressive phenomena and structural needs derived from underdevelopment, either due to forced migration for political reasons or for labor or cultural reasons, or others (BarDin 2008; Davis 1993, inter alia). (2) As a result of impoverishment produced by globalization (Mc Dowel, 1996; Sassen 1998). And (3) focusing on the tragic dimension of up-rootedness as Davis (1993:209).

${ }^{14}$ Pascal (1623-1662) plantea, en forma de paradoja, la distancia entre la razón y el bien actuar, como la irreductibilidad entre "la lógica de la razón" y "la lógica del corazón". Kierkegaard (1813-1855) también plantea la paradoja entre la búsqueda de la certeza y la fe, como lo que permite tal búsqueda. Russell (1872-1970) plantea su paradoja sobre los conjuntos en 1901: algunas clases se incluyen a sí mismas como miembros, la clase de los objetos abstractos es ella misma un objeto abstracto. Otras clases no, la clase de los burros no es ella misma un burro. Consideremos la clase de todas las clases que no son miembros de sí mismas. ¿Es esta clase miembro de sí misma? Si lo es, no lo es y si no lo es, entonces sí lo es. En términos menos abstractos, la coloquial sentencia del mentiroso: "si alguien te declara 'la verdad es que soy mentiroso', ¿te está diciendo que es mentiroso o que no lo es?” 
La aporía visibiliza la imposibilidad de resolver un problema de una vez por todas. Al abrir y mostrar el carácter insoluble de un dilema, se beneficia el proceso de conocimiento mismo, pues se despliegan alternativas posibles que no se visualizan en una lógica determinista o disyuntiva; opera como una forma particular de problematización que, en vez de forzar hacia una solución insostenible, asume la complejidad y la posibilidad de lo irresoluble. Me detendré en esta lógica para desmenuzar algunas de sus características.

Derrida, en su lectura de Heidegger, destaca la aporética de la decisión ética. Heidegger plantea que el nacimiento y la muerte son condiciones existenciales que muestran los límites de la capacidad de apropiación del sujeto (por eso no aceptaba la idea de sujeto o agente), los límites del dominio sobre el mundo o, si se quiere, la imposibilidad de domesticación de la existencia. Estos dos eventos, nacimiento y muerte, son los límites de ser situado o Dasein, suceden independientemente de su conciencia, voluntad y conocimiento. El nacimiento es precisamente condición para la muerte: no hay muerte sin nacimiento (y viceversa), y es desde ese ser-arrojado-a-la-existencia, a una existencia situada y hablada, desde donde se hace un llamado, una convocatoria al ser. Para Heidegger es el llamado a responder (responsabilidad) por algo que el ser-situado no domina, pero que es su condición existencial. Aquí es donde Derrida sitúa el plano ético: ser responsable ante algo que está fuera de los límites de dominio del Dasein.

Exponerse a una alteridad incalculable, fuera del dominio del sujeto, más allá de las normas sedimentadas es precisamente la decisión por encima de las normas, el conocimiento, los valores. Cuando no conozco la regla correcta, es cuando emerge la cuestión ética (Derrida, 2001), y es este desconocimiento lo que marca la imposibilidad, el comienzo no ético de la ética, la otredad de la ética como su condición de posibilidad. Es intentar pensar la posibilidad de lo imposible: comprender que la imposibilidad es precisamente condición para la posibilidad, y que es posible pensar lo imposible (Rafoul, 2004). ${ }^{15}$ El intento de domesticar lo que es imposible de ser domesticado, y precisamente porque es imposible se puede pensar siquiera en su posibilidad.

La indecidibilidad surge en la lógica matemática, y particularmente en el teorema de la incompletud del sistema matemático de Kurt Godel, ${ }^{16}$ aunque para lo que aquí interesa, se aborda como una estrategia de intelección que ofrece una alternativa a la lógica de

${ }^{15}$ En los riegos, Sócrates planteaba la aporía al asociar la virtud y el conocimiento. De ahí concluía que nadie hace daño sabiéndolo. Se ha considerado también como una forma de nombrar cuando surgen contradicciones o paradojas irresolubles; por ejemplo, la idea de "la nada" implica una aporía, pues supone la existencia de algo que por definición no existe.

${ }^{16}$ También conocidos como teoremas de lógica matemática, demostrados por Kurt Gödel en 1931. Ambos están relacionados con la existencia de proposiciones indecidibles en ciertas teorías aritméticas. Destacan dos planos: a) cuando un teorema no se puede resolver algorítmicamente; b) cuando la consistencia de un sistema debe establecerse desde otro sistema cuya consistencia, a su vez, no haya sido establecida por el primero. 
disyunción o dilema heredada (e.g. blanco o negro, interno o externo, caja de Pandora o panacea); comparte la lógica de la tensión constitutiva y nos permite jugar con una figura de conjunción aporética: algo que no es el dualismo clásico, ni el "justo medio" aristotélico, sino que permite mirar lo ambivalente, lo que es interno y a la vez externo. Por ejemplo, la frontera entre dos países, que a la vez que los separa los une; el tímpano, visto como la membrana que separa al oído medio del oído interno y a la vez los une (Derrida, 1987). No se trata de la pura indeterminación ni de la libre flotación del significante, sino de una condición estructural del lenguaje, que opera en la tensión irresoluble entre intención y estructura (intersección aporética) en un texto, y que hace posible la generación de significados particulares altamente específicos y con frecuencia opuestos. Esta lógica resiste tanto la binariedad como la estructura tríadica de elementos positivos; es lo que define los límites de lo decidible, lo calculable o la completud formalizable, y es lo que permanece heterogéneo a ambos significados. De acuerdo con lo que es ostensiblemente una paradoja, un indecidible abre el espacio para la decisión y la decidibilidad en el campo de la responsabilidad ético-política: es su condición necesaria.

En Políticas de la amistad, Derrida señala que una decisión sólo puede llegar a existir en un espacio que excede el programa calculable que destruiría toda responsabilidad, transformándola en un efecto programable de causas determinadas. No puede haber responsabilidad moral y ética sin esta prueba y este pasaje vía la indecidibilidad. Aún si la decisión parece tomar sólo un segundo y no estar precedida por deliberación alguna, se estructura por una experiencia y experimento de lo indecidible.

Lógicas como la paradoja, la aporía, la indecidibilidad, la sobredeterminación, entre otras, ofrecen herramientas de intelección que permiten observar el "entre-medio", la movilidad y porosidad de los límites, y ello a su vez habilita al intelecto para observar y entender las idas y venidas, los desarraigos y nuevas internalizaciones, las desidentificaciones y nuevas identificaciones; la gama de tonalidades entre blanco y negro, la posibilidad que sólo es en el marco de la imposibilidad; las decisiones posibles en los marcos indecidibles que atraviesan los migrantes en sus diversas experiencias, narraciones y ambientes; permiten ver más allá de las "ideas claras y distintas", de las oposiciones positivas del binarismo y el dualismo, de la causalidad necesaria y suficiente, y otras que supuestamente garantizan la certeza indiscutible del conocimiento.

Regresando a nuestro ejemplo, la migración ha sido estudiada como un resultado de la pobreza (Mc Dowel, 1996), la opresión y la ausencia de satisfactores -laborales, educativos, de salud y de transporte, etc. (Bar-Din, 2008; Davis, 1993, inter alia)-, que expulsan a las poblaciones a moverse a otros lugares de residencia (Valenzuela, 1999). Algunos trabajos la equiparan directamente con los resultados de la globalización del neoliberalismo (Sassen, 
1998); ${ }^{17}$ otros, directamente con la dimensión trágica del desarraigo, como señala Davis (1993: 209): “con todo y lo numerosos que son, la población en general los trata como si fueran invisibles; y esta población prefiere suponer que no se asimilan, que no aprenden inglés y que no están dispuestos a encajar en el sistema”.

Mi opción en este trabajo es menos por el juicio y más por la comprensión (análisis, interpretación) del fenómeno en su contexto, a partir de las narrativas de los protagonistas, y contrasta con lo que las lógicas binarias consagradas permiten visibilizar. De acuerdo con la investigación etnográfica multicitada, y recurriendo a las lógicas anteriormente presentadas,

- Esta condición existencial de pobreza y mínimo desarrollo que se puede observar en el entorno rural mencionado, en donde los jóvenes son arrojados, y la imposibilidad de dominar lo que en ella sucede, es una de las condiciones que opera en el despliegue de la resistencia, la perseverancia, la capacidad de recuperación, el triunfo sobre muchos obstáculos culturales, comunitarios, personales, institucionales e incluso gubernamentales, que narran muchos de los entrevistados. Esta condición de imposibilidad existencial de una vida mejor (a la cual son arrojados) opera también como un motor -junto con otras condicionantes- en la generación de las tácticas de supervivencia y las estrategias de adaptación e inserción en los espacios donde han asignado sus expectativas de superación. Así, el recurso intelectual de la paradoja y la aporía permite observar y dar cuenta de matices y operaciones finas que la lógica binaria no contempla.

- Cuando migran, sea por ingresar a una universidad o por trabajo, no se observan rupturas absolutas ni arraigos totales; estos migrantes rehacen su cultura y su relación con la familia y la comunidad: refuerzan algunos rasgos y se distancian de otros, llevan consigo algunas prácticas e hibridizan algunas más. Ellos no narran estas modificaciones culturales como algo trágico; en todo caso, sí como un obstáculo que han vencido, como una situación a la que se pueden adaptar, porque es representada como mejora. Solamente si quien investiga pretende ubicarse por encima de la historia y el contexto, y cree que existe la verdad trascendental, universal y única, al margen de su carácter situado y de la significación que los protagonistas le asignan, y que alguien (quien investiga) es poseedor de tal verdad, es posible aceptar la interpretación generalizada que sólo observa tragedia, desarraigo y desposesión como efecto global de la migración.

\footnotetext{
${ }^{17}$ Esta discusión y la historización de las migraciones se haya disponible en Buenfil (2009).
} 
- Los migrantes toman decisiones en marcos sumamente inestables, que exceden normatividades culturales y legales, sea de escala comunitaria, estatal, nacional e incluso internacional. Por ejemplo, los que cruzan la frontera se sitúan por afuera de la normatividad fronteriza norteamericana, lo cual potencia una situación de riesgo que asumen por conveniencia (ganar en dólares), por costumbre (todos los del Valle se van), por ingenuidad (alcanzar el sueño "americano") y por muchos otros motivos. Los que migran en el interior de la República Mexicana en busca de mejores condiciones escolares o laborales, tampoco responden a un imperativo categórico: hay muchas decisiones que podrían ser asumidas (incluso el delito), y ninguna es resultado de una programación algorítmica o exclusivamente de una necesidad estructural del desarrollo socioeconómico. Vemos en acción también condicionantes de la cultura de la comunidad, del imaginario de la Ilustración promovido en México desde el siglo XIX, de las influencias familiares y de redes culturales, sociales e institucionales diversas.

- En el ejemplo del entrevistado, el joven se piensa a sí mismo en el futuro, narra la situación familiar y significa la migración con una variedad de matices que una lógica binaria o dualista encontraría esquizofrénica, manipulativa o simplemente falsa, en la cual solamente el "lavado de cerebro" podría explicar que un joven ubicara la "tragedia" de salir de su comunidad (idílicamente concebida) como una actividad tan naturalizada como asistir a la escuela, o como ayudar a su familia o a su comunidad; también como una oportunidad de mejora, como un medio para "hacer lo que él quiere". Más en detalle, cuando a la pregunta 5: “¿Tus hermanos han salido a otros lugares a vivir?", la persona entrevistada responde: "No, todos viven en Jilotepec", uno de mis hermanos está trabajando en México. La incongruencia de decir que nadie ha salido y que todos viven en Jilotepec, seguida de que un hermano trabaja en México, abre no sólo una (se equivocó), sino diversas posibilidades de interpretación.

Aún con la tentación de sugerir generalizaciones, intentaré ceñirme al caso recuperado. Es evidente que las transformaciones culturales más amplias en el Valle del Mezquital pueden verse desde la perspectiva triunfalista que enfatiza los logros del individuo en correspondencia con los esfuerzos de las políticas públicas (posible lectura oficialista), en consonancia con una lógica evolucionista, etapista o teleológica, en la cual la historia es vista como progresión hacia estadios siempre superiores. También pueden explicarse desde la perspectiva de la dominación, originada (y determinada) por la desigualdad en las 
oportunidades de desarrollo y las restricciones que los jóvenes han tenido a sus libertades para decidir sus formas de desarrollo; una tercera perspectiva alcanza a reconocer una elección de los jóvenes - condicionada si se quiere, pero una elección al fin- para definir, hasta cierto punto, sus procesos de cambio y continuidad. La perspectiva de dominación suele coincidir con la lectura de la dimensión trágica y traumática y con las propuestas emancipatorias y de rescate y conservación de las culturas nativas (a veces entendidas como puras y bondadosas de suyo). En la tercera forma de interpretar, se reconoce el contacto y sincretismo cultural en sus comunidades (que no concuerda con la pureza ni siquiera en las comunidades precolombinas) y se observa la combinación con nuevos elementos de los cuales también se apropian en la búsqueda de ascenso social, vía laboral o escolar.

Si bien el tercer tipo de interpretación reconoce la fuerza, persistencia y resiliencia de los entrevistados, aún es posible incorporar recursos de intelección más finos y en consonancia con la evidente complejidad que los fenómenos acusan. El carácter indecidible de la estructura abre diversas posibilidades: en primer lugar, promueve la elección de algunas entre muchas posibilidades; en segundo, permite la generación de posibilidades opuestas, pero además habilita el reconocimiento de que esta oposición no alude a dos cualidades independientes que se rechazan, sino a dos extremos de un mismo fenómeno. Esto a su vez nos permite observar que son codependientes: hay triunfo, porque hay obstáculo; hay logro, porque hay desafío; hay empoderamiento, porque hay dominación; hay horizonte de futuro mejor, porque hay condiciones de un presente de limitaciones. A esto nos invita Derrida (1998): a ser responsable ante algo que está fuera de los límites de nuestro dominio. A pensar la posibilidad de lo imposible.

\section{REFERENCIAS}

Althusser, L. (1969). La revolución teórica de Marx. México: Siglo XXI.

BAR-Din, A. (2008). La vida de los trabajadores latinos contada por ellos mismos. México: CIALCFFYL-UNAM-Siglo XXI.

Buenfil Burgos, R. N. (2016). Theoretical and Political Resources: Between Analysis And Judgment. Practicing Anthropology, 38(1), Winter.

. (2009). Politics, global territories and educational spaces. In Popkewitz, T. \& Rizvi, F. (Eds.), Globalization and the study of education (pp. 67-88). Massachusetts: WilleyBlackwell.

. (2008). La categoría intermedia. En Cruz y Echavarría (Coords.), Investigación social. Herramientas teóricas y Análisis Político de Discurso (pp. 29-40). México: Juan PablosPrograma de Análisis Político de Discurso e Investigación (PAPDI). 
- (2006). Los usos de la teoría en la investigación educativa. En JimÉNEZ, M.A. (Coord.), Los usos de la teoría en la Investigación (pp. 37-60). México: Plaza y ValdésSeminario de Análisis del Discurso Educativo.

, y Navarrete, Z. (2011). Aproximaciones político discursivas. En Discursos Educativos, identidades y formación profesional (pp. 11-35). México: Plaza y Valdés-PAPDI.

Burke, P. (2002). Historia social del conocimiento: de Gutenberg a Diderot. Barcelona: Paidós.

DAVIS, M. (1993). Voces mexicanas. Sueños americanos. México: Siglo XXI Editores.

Deleuze, G. (1991). Foucault. México: Paidós.

DERRIDA, J. (1987). Márgenes de la Filosofía. Madrid: Cátedra. . (1998). Políticas de la amistad. Madrid: Trotta.

. (1997). El tiempo de una tesis y Carta al amigo japonés. En El Tiempo de una tesis. Desconstrucción e implicaciones conceptuales (pp. 11-22, 23-27). Barcelona: Proyecto A Ediciones.

DesCARTES, R. (1977 [1647]). Meditaciones Metafísicas. Madrid: Alfaguara.

DiDEROT, D. (1772 [1751]). L'Encyclopédie o Dictionnaire raisonné des sciences, des arts et des métiers. París.

ECHAVARRÍA, L. (2007). El cuerpo maquilador como sujeto de la globalización. Mundo laboral y políticas educativas en México. 1990-2000. Tesis de Maestría. México: UNAM.

Foucault, M. (1979). La Microfísica del poder. Madrid: Ediciones de La Piqueta.

GODEL, K. (2006 [1931]). Sobre proposiciones formalmente indecidibles de los Principia Mathematica y sistemas afines. KRK Ediciones.

Gómez Gallegos, M. A. (2012). Nuevas dimensiones de las categorías étnicas convencionales: Buscando estudiantes indígenas en una universidad tecnológica de Hidalgo. Tesis de Doctorado. México: DIE CINVESTAV.

HeGEl, F. (1966). Fenomenología del espíritu. México: FCE.

HeidegGer, M. (1951). El ser y el tiempo. Traducción de José Gaos. México: FCE.

HUSSERL, E. (1997). Ideas relativas a una fenomenología pura y una filosofía fenomenológica. Libro Primero. Traducción de José Gaos. México: FCE.

. (1994). Problemas fundamentales de la fenomenología. Traducción de César Moreno y Javier San Martín. Madrid: Alianza Editorial.

JimÉnEZ, M. A. (Coord.) (2006). Los usos de la teoría en la Investigación Educativa. México: Plaza y Valdés-SADE.

KuHN, T. (1971). La estructura de las revoluciones científicas. México: FCE.

LÉVI-STRAuSS, C. (1968 [1958]). Antropología estructural. Buenos Aires: Editorial Universitaria de Buenos Aires. 
NAVARRETE, Z. (2008). Construcción de una categoría intermedia: ethos profesional. En CRUZ y ECHAVARRÍa (Coords.), Investigación social. Herramientas teóricas y Análisis Político de Discurso (pp. 41-56). México: Juan Pablos-PAPDI.

Heidegger, M. (1989 [1927]). Ser y Tiempo. México: FCE.

KierkegaARD, S. (1980 [1849]). Diario de un seductor. Barcelona: Ediciones 29. . (1855 [1813]). Fear and trembling and The sickness unto death. London: Penguin Classics.

LaClau, E., Mouffe, C. (1987). Más allá de la positividad de lo social. En Hegemonía y Estrategia Socialista (pp. 105-166). México: Siglo XXI.

MC Dowel, C. (Ed.) (1996). Understanding Impoverishment: The Consequences of Developmentinduced Displacement. London, United Kingdom: Berghahn Books.

Orozco, B. (2006). Usos de la teoría para interrogar la realidad: reto para la formación universitaria. En JimÉnEZ, M. A. (Coord.) (2006), Los usos de la teoría en la Investigación Educativa (pp. 101-117). México: Plaza y Valdés-SADE.

Pascal, B. (1975). A Concordance to Pascal's Pensées. En Davidson, H. M. \& Dubé, P. H. (Eds.), Ithaca. Cornell University Press.

PAdierna, M. P. (2009). Construcción de foros para la práctica ciudadana: mujeres zapatistas. En Soriano y Ávalos (Coords.), En Análisis Político de Discurso. Dispositivos intelectuales en la investigación social (pp. 65-73). México: Juan Pablos-PAPDI.

QUESADA, M.F. (2008). La migración hñahñú del valle de Mezquital, Estado de Hidalgo. México: CDI.

RAFOUL, F. (2004). The possibility of the impossible: Heidegger and Derrida on responsibility. Bulletin de la Société Americaine de Philosophie de Langue Française, 14 (1), pp. 43-60.

REMEDI, E. (2007). Comentario al libro Horizontes de intelección en la Investigación Educativa: Discursos, Identidades y Sujetos. En FuENTES, S. (Coord.). IX CNIE. Mérida (inédito).

. (2004). Intervenciones. En García SAlord, S., Hickman, H. y LANDESman, M., Taller Cocina de la Investigación. México: IMAS-UNAM (inédito)

Ruiz, M. M. (2005). Imbricación de lo político y lo pedagógico en los procesos de educación de adultos. Dos estudios de caso. México: CREFAL.

RORTY, R. (1991). Contingencia, ironía y solidaridad. México: Paidós.

Ruiz, M. (2005). Imbricación de lo político y lo pedagógico en los procesos de educación de adultos. Dos estudios de caso. México: Centro de Cooperación Regional para la Educación de Adultos en América Latina y el Caribe.

RuSSELL, B. (1970 [1919]). Introduction to mathematical philosophy. London: Allen. 
. (1964). Appendix B: The Doctrine of Types. In The Principles of Mathematics, prefácio à primeira edição. Northampton: John Dickens \& Co LTD.

SASSEN, S. (1998). Globalization and Its Discontents. Essays on the New Mobility of People and Money. The New York Press.

SAUR, D. (2008a). ¿Aplicar la teoría? Reflexiones en torno a la noción de aplicación en análisis de discurso. En Memorias del II Encuentro Internacional Giros Teóricos. CD (Versión impresa dictaminada y en formación editorial). . (2008b). Categorías intermedias y producción de conocimiento. En Saur y Da Porta (Coords.). Giros Teóricos en las Ciencias Sociales y Humanidades (pp. 63-71). Córdoba, Argentina: Comunicarte.

Staten, H. (1985). Wittgenstein and Derrida. Oxford: Basil Blackwell.

VALENZUELA, M. B. (1999). Las condiciones de llegada y asentamiento de nuevos migrantes en ciudades globales. El caso de los mexicanos en el Harlem hispano de Nueva York. Papeles de Población (22).

WitTGenstein, L. (1953). Investigaciones Filosóficas. México: Alianza IIF-UNAM. 